\title{
Research of Active Power Filter Modeling with Grid Impedance in Feedback Linearization and Quasi-Sliding Mode Control
}

\author{
Zeyu Shi, ${ }^{1}$ Yingpin Wang, ${ }^{1}$ Yunxiang Xie, ${ }^{1}$ Lanfang $\mathrm{Li}^{2}$, and Xiaogang Xu \\ ${ }^{1}$ School of Electric Power, South China University of Technology, Guangzhou 510640, China \\ ${ }^{2}$ Electric Power Research Institute, Guangdong Power Grid Co. Ltd., Guangzhou 510080, China \\ Correspondence should be addressed to Yingpin Wang; wangyingppp@126.com
}

Received 5 May 2017; Accepted 19 October 2017; Published 21 November 2017

Academic Editor: Hung-Yuan Chung

Copyright (c) 2017 Zeyu Shi et al. This is an open access article distributed under the Creative Commons Attribution License, which permits unrestricted use, distribution, and reproduction in any medium, provided the original work is properly cited.

Active power filter (APF) is the most popular device in regulating power quality issues. Currently, most literatures ignored the impact of grid impedance and assumed the load voltage is ideal, which had not described the system accurately. In addition, the controllers applied PI control; thus it is hard to improve the compensation quality. This paper establishes a precise model which consists of APF, load, and grid impedance. The Bode diagram of traditional simplified model is obviously different with complete model, which means the descriptions of the system based on the traditional simplified model are inaccurate and incomplete. And then design exact feedback linearization and quasi-sliding mode control (FBL-QSMC) is based on precise model in inner current loop. The system performances in different parameters are analyzed and dynamic performance of proposed algorithm is compared with traditional PI control algorithm. At last, simulations are taken in three cases to verify the performance of proposed control algorithm. The results proved that the proposed feedback linearization and quasi-sliding mode control algorithm has fast response and robustness; the compensation performance is superior to PI control obviously, which also means the complete modeling and proposed control algorithm are correct.

\section{Introduction}

Active power filter (APF) is the most popular device in harmonics compensation; it commonly consists of current filter, electronic converter, and DC-link capacitor. The APF connected to grid and compensated power quality problems [1].

Recently, the interactions between grid connected devices and the grid have drawn greater attention [2]. However, most literatures established the model of isolated APF and rarely consider the impact of grid impedance [3]. Thus the descriptions of the system based on the traditional simplified model are inaccurate and incomplete. If the mathematical models of the grid impedance and the loads were contained in the APF control system, then the specific effects of each of them could be studied more accurately and completely [4]
In recent decades, nonlinear control theory has made a great progress, especially feedback linearization (FBL) theory based on differential geometry. Feedback linearization control can achieve global linearization by using a certain nonlinear state transformation or feedback transformation [5]. All these methods can solve the problem of nonlinear system and obviously improve static and dynamic performance. Yet, this control method depends on an accurate mathematical model and is sensitive to system parameters [6]. There are many literatures that adopted feedback linearization in three-phase APF [7] and single-phase APF [8]. However, none of them consider the impact of grid impedance. Thus, the optimum performance of APF has not been achieved.

Sliding mode control shows great robustness and fast convergence when the system is running in the sliding surface [9]. Thus, slide model control (SMC) is adopted to increase 


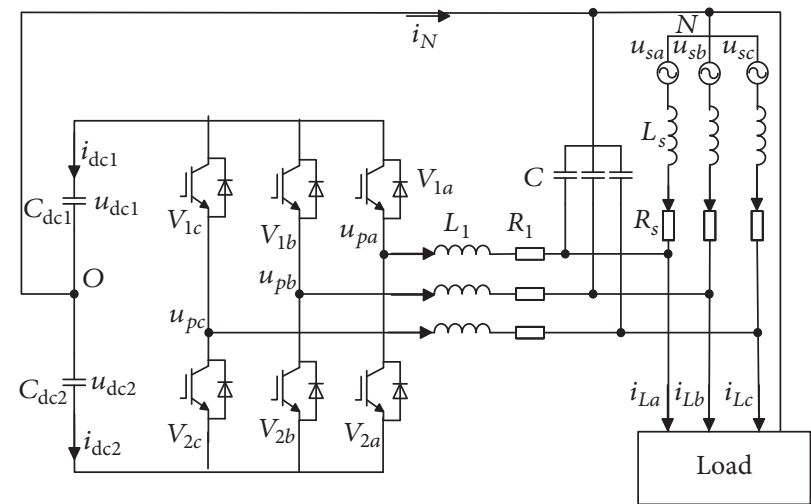

FIGURE 1: Structure of LC APF with grid impedance.

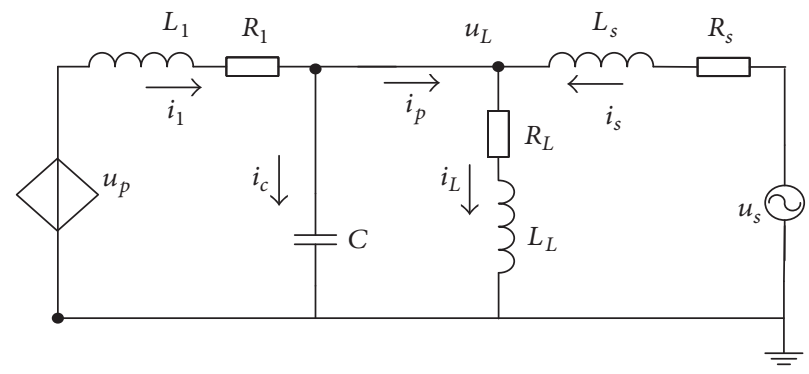

FIGURE 2: Single-phase circuit diagram of $L C$ APF with grid impedance.

the robustness in model uncertainties and reduce disturbance responses [10]. In [11], sliding mode control has been applied to the three-phase APF and achieved a good result.

This paper establishes a precise model consisting of APF, load, and grid impedance. And then it applies exact feedback linearization and quasi-sliding mode control method (FBLQSMC) in inner current loop. At last, it analyzes the performances of proposed algorithm and compares with traditional PI control algorithm in dynamic respond and simulation.

\section{Mathematical Model of APF with Grid Impedance}

The structure diagram of LC APF with grid impedance is shown in Figure 1. Because a three-phase APF system is symmetrical, the system is analyzed with its single-phase circuit [12]. The single-phase circuit diagram of an APF with current controller is shown in Figure 2.

In Figure 2, $u_{\mathrm{dc}}$ is voltage of DC-link, $C_{\mathrm{dc}}$ is capacitor of DC-link, $u_{p}$ is output voltage of converter, $i_{1}$ is output current of converter, $L_{1} / R_{1}$ is filter impedance, $C$ is filter capacitor, $i_{p}$ is current of APF compensating, $u_{L}$ is voltage in load side, $i_{L}$ is load current, $L_{L} / R_{L}$ is equivalent impedance of load, $L_{s} / R_{s}$ is grid impedance, and $u_{s}$ is grid voltage.

From Figure 2, there are the following equations:

$$
\begin{aligned}
L_{s} \frac{d i_{s}}{d t} & =-R_{s} i_{s}+u_{s}-u_{L}, \\
L_{L} \frac{d i_{L}}{d t} & =-R_{L} i_{L}+u_{L},
\end{aligned}
$$

$$
\begin{aligned}
& L_{1} \frac{d i_{1}}{d t}=-R_{1} i_{1}+u_{p}-u_{L} \\
& C \frac{d u_{L}}{d t}=i_{1}-i_{p}
\end{aligned}
$$

where $i_{p}=i_{L}-i_{s}$.

The role of inner current loop is keeping source current $i_{s}$ tracking with reference current $i_{s}^{*}$ and realizing system unity power factor operation. This paper applies feedback linearization in inner current loop, designed state variables are $\mathbf{X}=\left[\begin{array}{llll}x_{1} & x_{2} & x_{3} & x_{4}\end{array}\right]^{T}=\left[\begin{array}{llll}i_{s} & i_{L} & i_{1} & u_{L}\end{array}\right]^{T}$, input variable is $u=u_{p}$, and the output variable is $Y=h(\mathbf{X})=x_{1}$. The following affine nonlinear equations are obtained.

$$
\begin{aligned}
& \dot{\mathbf{X}}=\mathbf{f}(\mathbf{X})+\mathbf{g}(\mathbf{X}) u, \\
& \mathbf{Y}=\mathbf{h}(\mathbf{X}),
\end{aligned}
$$

where

$$
f(X)=\left[\begin{array}{c}
-\frac{R_{s}}{L_{s}} x_{1}-\frac{1}{L_{s}} x_{4}+\frac{u_{s}}{L_{s}} \\
-\frac{R_{L}}{L_{L}} x_{2}+\frac{1}{L_{L}} x_{4} \\
-\frac{R_{1}}{L_{1}} x_{3}-\frac{1}{L_{1}} x_{4} \\
\frac{1}{C} x_{1}-\frac{1}{C} x_{2}+\frac{1}{C} x_{3}
\end{array}\right],
$$




$$
g(X)=\left[\begin{array}{c}
0 \\
0 \\
\frac{1}{L_{1}} \\
0
\end{array}\right]
$$

\section{Control System Design}

\subsection{Feedback Linearization of APF with Grid Impedance}

Lemma 1. $L_{f} h(X)$ and $L_{g} h(X)$ are the Lie derivatives of $h(\mathbf{X})$ with respect to $f(\mathbf{X})$ and $g(\mathbf{X})$. If $L_{g} L_{f}^{k} h(x)=0$ for all $k<r-1$, and $L_{g} L_{f}^{r-1} h(x) \neq 0$, that means the system's relative degree is $r$ [8].

Taking Lie derivative for (2), the following is obtained:

$$
\begin{aligned}
L_{g} h(X) & =0, \\
L_{g} L_{f} h(X) & =0, \\
L_{g} L_{f}^{2} h(X) & =-\frac{1}{\left(C * L_{1} * L_{S}\right)}, \\
L_{g} L_{f}^{3} h(X) & =\frac{\left(R_{S} /\left(C * L_{S}^{2}\right)+R_{1} /\left(C * L_{1} * L_{S}\right)\right)}{L_{1}} .
\end{aligned}
$$

From (4), the relative degree $r=3$ is less than the system dimension $n=4$, which means the nonlinear systems are designed to be minimum phase with its zero dynamics. Because the zero dynamics are assumed to be globally stable, the state variables converge and so does the closed-loop system [13].

After taken Lie derivative obtained the variables transformation, the state equations of APF with grid impedance control system altered to

$$
\mathbf{Z}=\left[\begin{array}{c}
\xi_{1} \\
\xi_{2} \\
\xi_{3} \\
\eta_{1}
\end{array}\right]=\left[\begin{array}{c}
h(\mathbf{X}) \\
L_{f} h(\mathbf{X}) \\
L_{f}^{2} h(\mathbf{X}) \\
\eta_{1}
\end{array}\right]=\left[\begin{array}{c}
x_{1} \\
-\frac{R_{S} x_{1}}{L_{s}}-\frac{x_{4}}{L_{s}}+\frac{U_{s}}{L_{s}} \\
x_{1}\left(\frac{R_{S}{ }^{2}}{L_{S}{ }^{2}}-\frac{1}{\left(C L_{S}\right)}\right)+\frac{1}{\left(C L_{S}\right) x_{2}}-\frac{x_{3}}{\left(C L_{S}\right)}+\frac{x_{4} R_{S}}{L_{S}{ }^{2}}-\frac{U_{S} R_{S}}{L_{S}{ }^{2}}+\frac{\dot{U}_{s}}{L_{s}}
\end{array}\right]
$$

Thus,

$$
\begin{aligned}
& x_{1}=\xi_{1}, \\
& x_{2}=\eta_{1}, \\
& x_{3}=-\xi_{1}-\xi_{2} R_{S} C-\xi_{3} C L_{S}+\eta_{1}+\dot{U}_{S} C, \\
& x_{4}=U_{S}-R_{S} \xi_{1}-L_{S} \xi_{2} .
\end{aligned}
$$

There are

$$
\begin{aligned}
& \dot{\xi}_{1}=\xi_{2}, \\
& \dot{\xi}_{2}=\xi_{3}, \\
& \dot{\xi}_{3}=b(\xi, \eta)+a(\xi, \eta) u, \\
& \dot{\eta}_{1}=-\frac{R_{L}}{L_{L}} \eta_{1}+\frac{1}{L_{L}}\left(U_{S}-R_{S} \xi_{1}-L_{S} \xi_{2}\right) .
\end{aligned}
$$

Since the state variables converge to zero due to the linear characteristics, the closed-loop trajectories can be well controlled. Furthermore, some assumption must be applied to the fourth equation of (7) [13]:

$$
\dot{\eta}=q(0, \eta) \quad \text { for } t \longrightarrow \infty
$$

That is,

$$
\dot{\eta}_{1}=-\frac{R_{L}}{L_{L}} \eta_{1}+\frac{U_{S}}{L_{L}} .
$$

Equation (9) shows zero dynamics is bounded and exponentially stable.

In (7), $a(\xi, \eta)=L_{g} L_{f}^{2} h(X)$ and $b(\xi, \eta)=L_{f}^{3} h(X)$, assuming the new input is $\dot{\xi}_{3}=\dddot{\xi}_{1}=v$, the original nonlinear state equations can be written as standard linear equation:

$$
\dot{\mathbf{Z}}=\left[\begin{array}{lll}
0 & 1 & 0 \\
0 & 0 & 1 \\
0 & 0 & 0
\end{array}\right] \mathbf{Z}+\left[\begin{array}{l}
0 \\
0 \\
1
\end{array}\right] v
$$

The input transformation can be expressed as

$$
u=\frac{-L_{f}^{3} h(\mathbf{X})+v}{L_{g} L_{f}^{2} h(\mathbf{X})} .
$$

The equivalent control input of feedback linearization is

$$
u_{\mathrm{eq}}=-\frac{L_{f}^{3} h(\mathbf{X})}{L_{g} L_{f}^{2} h(\mathbf{X})} .
$$


In Lie derivative

$$
\begin{aligned}
L_{g} L_{f}^{2} h(X)= & -\frac{1}{\left(C L_{1} L_{S}\right)}, \\
L_{f}^{3} h(\mathbf{X})= & K_{1} x_{1}+K_{2} x_{2}+K_{3} x_{3}+K_{4} x_{4}+\frac{\ddot{U}_{S}}{L_{S}} \\
& -\frac{\dot{U}_{S} R_{S}}{L_{S}^{2}}-\frac{U_{S}}{\left(C L_{S}^{2}\right)}+\frac{R_{S}^{2} U_{S}}{L_{S}^{3}},
\end{aligned}
$$

where

$$
\begin{aligned}
& K_{1}=\frac{\left(R_{S} /\left(C L_{S}\right)-R_{S}^{3} / L_{S}^{2}\right)}{L_{S}}+\frac{R_{S}}{\left(C L_{S}^{2}\right)}, \\
& K_{2}=-\left(\frac{R_{S}}{\left(C L_{S}^{2}\right)}+\frac{R_{L}}{\left(C L_{L} L_{S}\right)}\right), \\
& K_{3}=\frac{R_{S}}{\left(C L_{S}^{2}\right)}+\frac{R_{1}}{\left(C L_{1} L_{S}\right)}, \\
& K_{4}=\frac{\left(1 /\left(C L_{1}\right)+1 /\left(C L_{L}\right)+1 /\left(C L_{S}\right)\right)}{L_{S}}-\frac{R_{S}^{2}}{L_{S}^{3}} .
\end{aligned}
$$

Thus

$$
\begin{aligned}
u_{\mathrm{eq}} & =C L_{1} L_{S}\left(K_{1} x_{1}+K_{2} x_{2}+K_{3} x_{3}+K_{4} x_{4}+\frac{\ddot{U}_{S}}{L_{S}}\right. \\
& \left.-\frac{\dot{U}_{S} R_{S}}{L_{S}^{2}}-\frac{U_{S}}{\left(C L_{S}^{2}\right)}+\frac{R_{S}^{2} U_{S}}{L_{S}^{3}}\right) .
\end{aligned}
$$

3.2. Quasi-Sliding Mode Controller Design. Quasi-sliding mode control (QSMC) can eliminate the chattering of sliding mode and keep stable and thus is used in widespread manner recently [14].

From the above analysis it is known that this is a 3-order system, and $e=x_{1}-x_{1 \mathrm{ref}}$, thus defining the sliding surface as

$$
s=c_{2} \ddot{e}+c_{1} \dot{e}+e .
$$

In QSMC, reaching law is designed as

$$
\dot{s}=-\varepsilon \cdot \operatorname{sat}(s),
$$

where

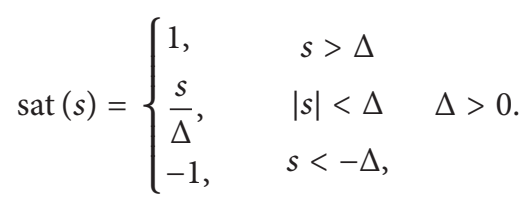

$$
\begin{aligned}
& \varepsilon>0 \text {. }
\end{aligned}
$$

Consider a positive augmented Lyapunov candidate as

$$
V=\frac{1}{2} \lambda s^{2}
$$

where $\lambda>0$ is a design parameter.
The time derivative of $V$ is

$$
\dot{V}=\lambda s \dot{s} .
$$

Substituting (16) and (17) into (20) obtains

$$
\dot{V}=-\lambda \varepsilon s \cdot \operatorname{sat}(s) \leq 0 .
$$

By the Lyapunov theorem of stability and LaSalle's invariance principle, the control system is proved to be stable.

Based on (7), there are

$$
\begin{aligned}
\dot{s} & =c_{2} \ddot{e}+c_{1} \ddot{e}+\dot{e} \\
& =c_{2}\left(b(x)+a(x) u-\ddot{x}_{1 \mathrm{ref}}\right)+c_{1} \ddot{e}+\dot{e} .
\end{aligned}
$$

Thus

$$
u=\frac{\left(\left(\varepsilon \cdot \operatorname{sat}(s)-c_{1} \ddot{e}-\dot{e}\right) / c_{2}+\ddot{x}_{1 \mathrm{ref}}-b(x)\right)}{a(x)} .
$$

The above equation can be taken as

$$
u=u_{\mathrm{eq}}+u_{s w}
$$

where

$$
u_{s w}=\frac{\left(\left(\varepsilon \cdot \operatorname{sat}(s)-c_{1} \ddot{e}-\dot{e}\right) / c_{2}+\ddot{x}_{1 \mathrm{ref}}\right)}{a(x)} .
$$

There is

$$
\begin{aligned}
u_{s w}= & -\left(\frac{\left(\varepsilon \cdot \operatorname{sat}(s)-c_{1} \ddot{e}-\dot{e}\right)}{c_{2}}+\dddot{x}_{1 \mathrm{ref}}\right) \\
& * C L_{1} L_{S} .
\end{aligned}
$$

After designing, $c_{1}=4 \times 10^{-4}, c_{2}=10^{-9}, \varepsilon=100, \Delta=10$.

\subsection{Implementation of Feedback Linearization Sliding Mode} Control. The control diagram of feedback linearization quasi-sliding mode control (FBL-QSMC) is shown in Figure 3. The control system consists of outer voltage loop and inner current loop. The outer voltage loop applied PI control, and the inner current loop applied FBL-QSMC control. It is necessary to remind that there are three identical inner current loops in three phases, respectively. However, there is only drawn one phase in the diagram.

As shown in Figure 3, the source reference active current $i_{r d}$ is equal to the sum of load's active current $i_{L d}^{*}$ and DC-link voltage regulating current $i_{\mathrm{dc}}^{*}$; the reference reactive current $i_{r q}$ and zero sequence current are equal to zero. After Park's transformation, the reference current from $d q 0$ coordinate transformed to $a b c$ coordinate. The reference current $i_{r a b c}$ subtracts the source current $i_{\text {sabc }}$ which obtains the source error current $e_{a b c}$ in $a b c$ phase, respectively. The source error current $e_{a b c}$ applied sliding mode control obtains switching input $u_{s w}$ and state variables in feedback linearization control obtain equivalent control input $u_{\text {eq }}$ and then sum up them equal to the control input signal $u$. 


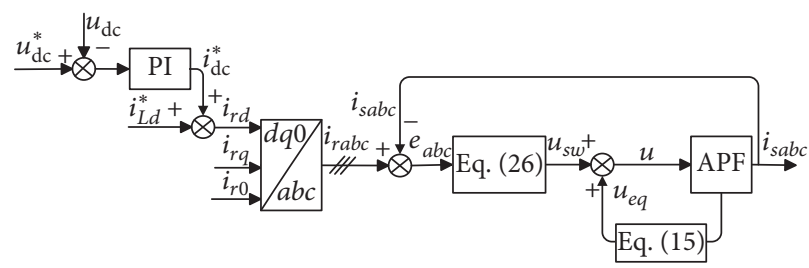

FIgURE 3: Control diagram of three-phase four-wire APF.

TABLE 1: System parameters.

\begin{tabular}{lc}
\hline Parameters & Value \\
\hline RMS source voltage $\left(U_{s}\right)$ & $380 \mathrm{~V}$ \\
Fundamental frequency $(f)$ & $50 \mathrm{~Hz}$ \\
$L$ filter $\left(L_{1} / R_{1}\right)$ & $0.6 \mathrm{mH} / 0.025 \Omega$ \\
$C$ filter $(C)$ & $10 \mu \mathrm{F}$ \\
Grid impedance $\left(L_{s} / R_{s}\right)$ & $0.03 \mathrm{mH} / 0.5 \Omega$ \\
Load equivalent impedance $\left(L_{L} / R_{L}\right)$ & $0.7 \mathrm{mH} / 3.6 \Omega$ \\
DC-side desired voltage $\left(V_{\mathrm{dc}}\right)$ & $700 \mathrm{~V}$ \\
DC-side capacitor $\left(C_{\mathrm{dc}}\right)$ & $5000 \mu \mathrm{F}$ \\
\hline
\end{tabular}

\section{Analysis of System Performance}

The system parameters are listed in Table 1.

4.1. Analysis of Transfer Functions. In traditional method [15], the LC filter is designed based on the transfer function of converter output voltage $u_{p}$ to load voltage $u_{L}$ without load and grid impedance. The transfer function is

$$
t u_{p} 2 u_{L}=\frac{1}{L_{1} C s^{2}+C R_{1} s+1} .
$$

In traditional model, it is unable to obtain the transfer relationship of converter output voltage $u_{p}$ to source current $I_{s}$. Only the relationship of converter output voltage $u_{p}$ to converter output current $I_{1}$ is obtained, in assuming the load voltage $u_{L}$ is constant, such that

$$
t u_{p} 2 I_{1}=\frac{1}{L_{1} s+R_{1}} .
$$

The resonant frequency $f_{r}$ is

$$
f_{r}=\frac{1}{2 \pi \sqrt{L_{1} C}} .
$$

Substitute the system parameters $L_{1}$ and $C$ into (29); the resonant frequency $f_{r}=2055 \mathrm{~Hz}$.

From the above equations, applying Matlab obtained the transfer functions and the Bode diagrams are shown in Figure 4.

In Figure 4 , the line " $u_{p} 2 I_{s}$ " is represented transfer function of converter output voltage $u_{p}$ to source current $I_{s}$ in proposed model; the line " $u_{p} 2 u_{L}$ " is represented transfer function of converter output voltage $u_{p}$ to load voltage $u_{L}$ in proposed model; the line " $u_{p} 2 I_{1}$ " is represented transfer function of converter output voltage $u_{p}$ to converter output current $I_{1}$ in proposed model; the line " $t u_{p} 2 u_{L}$ " is represented transfer function of converter output voltage $u_{p}$ to load voltage $u_{L}$ in traditional model; the line " $u_{p} 2 I_{1}$ " is represented transfer function of converter output voltage $u_{p}$ to converter output current $I_{1}$ in traditional model.

From Figure 4 it is seen that the frequency characteristics of traditional simplified model are obviously different with proposed precise model, which means the traditional model cannot describe the system correctly. Thus it is necessary to establish a precise model for analyzing parameters and designing controller.

4.2. Impact of Grid Impedance. The Bode diagram of converter output voltage $u_{p}$ to source current $I_{s}$ " $u_{p} 2 I_{s}$ " in different grid inductive impedance $L_{s}$ is shown in Figure 5.

From Figure 5 it is seen that with the grid inductive impedance increasing the high frequency magnitude of $I_{s}$ decreases, and the resonant frequency also decreases.

The Bode diagram of converter output voltage $u_{p}$ to source current $I_{s}$ " $u_{p} 2 I_{s}$ " in different grid resistance $R_{s}$ is shown in Figure 6.

From Figure 6 it is seen that with the grid resistance increasing the steady magnitude of $I_{s}$ decreases, and the resonant quality factor decreases.

4.3. Comparison of Control Systems. In PI controller, the parameters are inner loop proportionality coefficient $K_{p}=$ 10 , integral coefficient $K_{i}=2000$, outer loop proportionality coefficient $K_{p}=1$, and integral coefficient $K_{i}=1000$.

In FBL-QSMC controller, the inner loop is based on equivalent input $u_{\text {eq }}$ and QSMC input $u_{s w}$, the outer loop is based on PI controller, the proportionality coefficient $K_{p}=1$, and integral coefficient $K_{i}=1000$.

Comparison of the step response performances is shown in Figure 7.

From Figure 7 it is known that in PI controller converges slowly. However, FBL controller responds quickly and converges fast.

In cos signal input, the responses of PI controller and FBL controller are shown in Figure 8.

From Figure 8 it is known that in PI controller the convergence time is more than a period. However, FBL controller responds quickly and converges fast. 


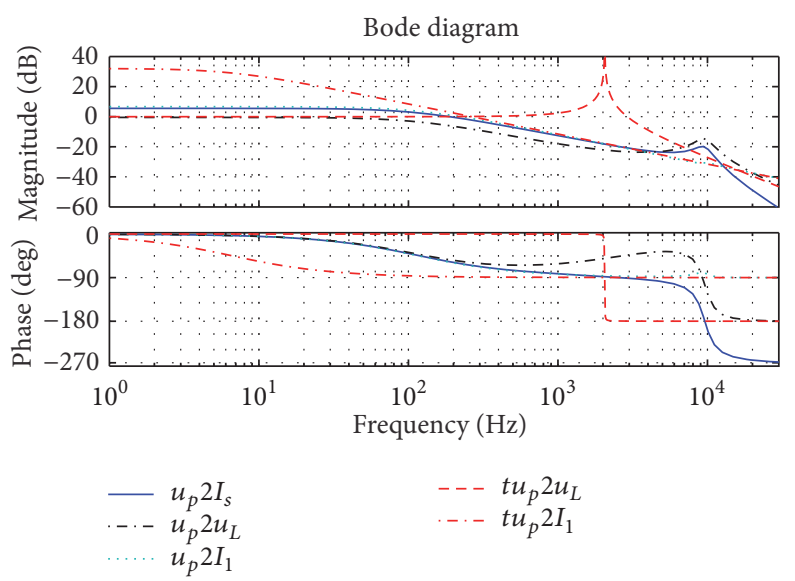

FIgURE 4: Bode diagram of transfer functions.

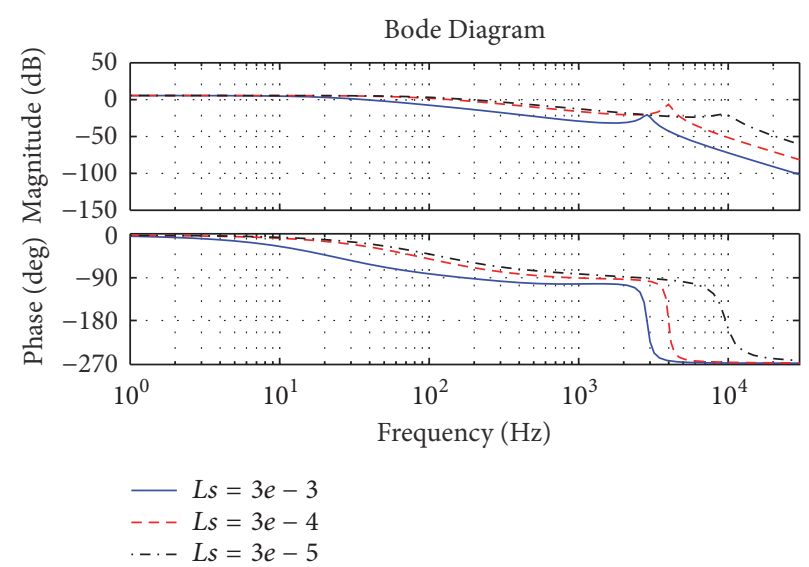

Figure 5: Bode diagram of $u_{p} 2 I_{s}$ in different $L_{s}$.

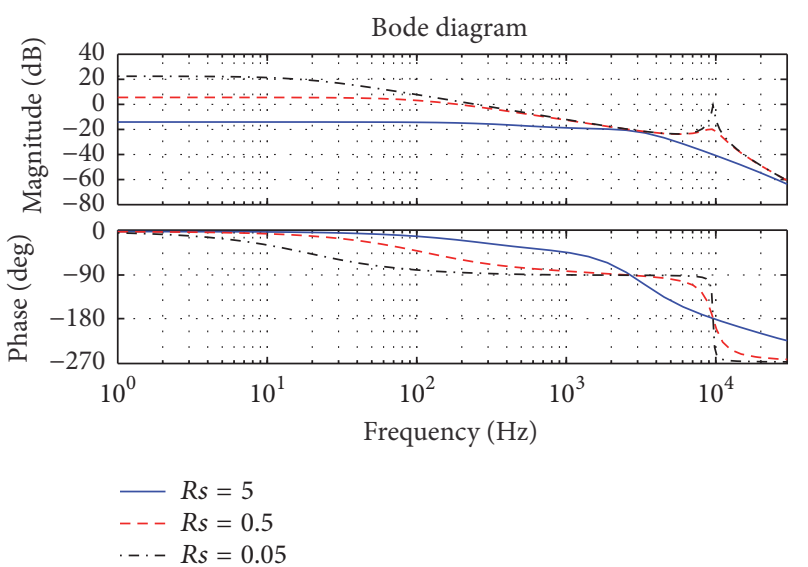

FIgURE 6: Bode diagram of $u_{p} 2 I_{s}$ in different $R_{s}$.

\section{Simulation Analysis}

The simulations are in Matlab/Simulink; the simulation parameters are listed in Table 1. The load consists of both linear and nonlinear type. The system is analyzed for different operating conditions as discussed in the following cases.
5.1. Case 1: Load Change. Cutting down nonlinear load at $t=$ $0.105 \mathrm{~s}$, the results in PI controller are shown in Figure 9, and the results in FBL-QSMC controller are shown in Figure 10.

In Figure 9(a), the upper part is load current and source current, the total harmonic distortion (THD) of large load current is $16.25 \%$, the THD of source current is $4.98 \%$, the 


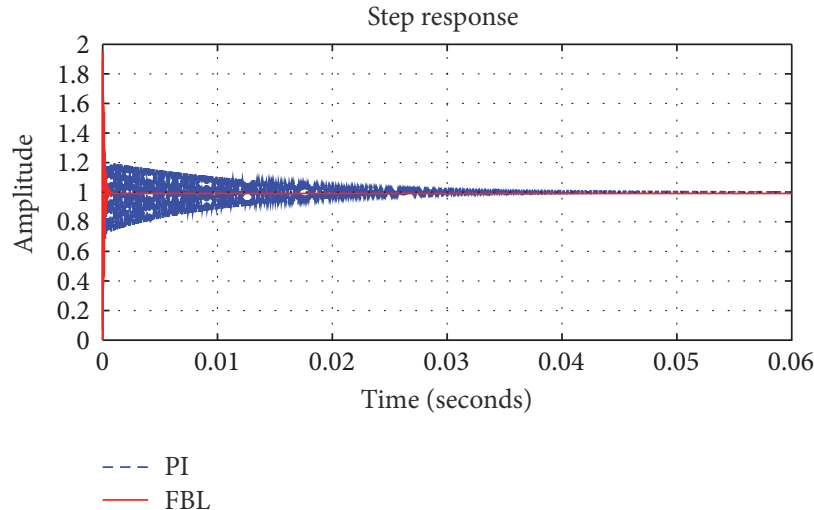

Figure 7: Step response in different controller.

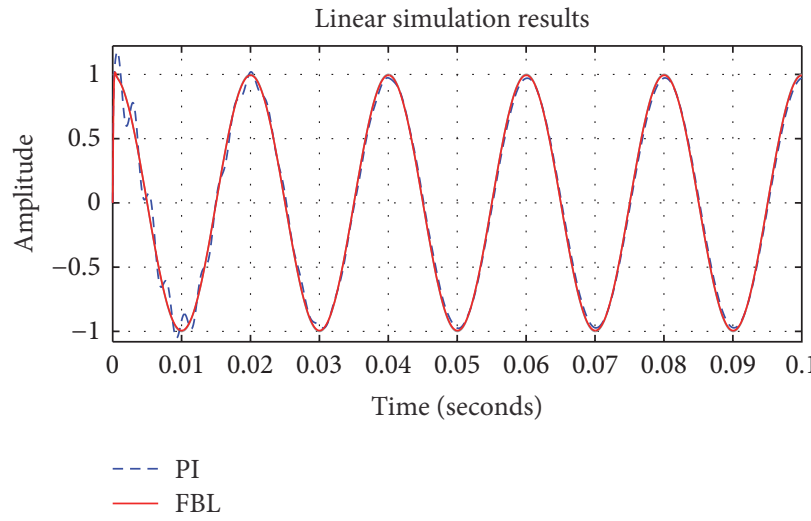

FIGURE 8: Cos input response in different controller.
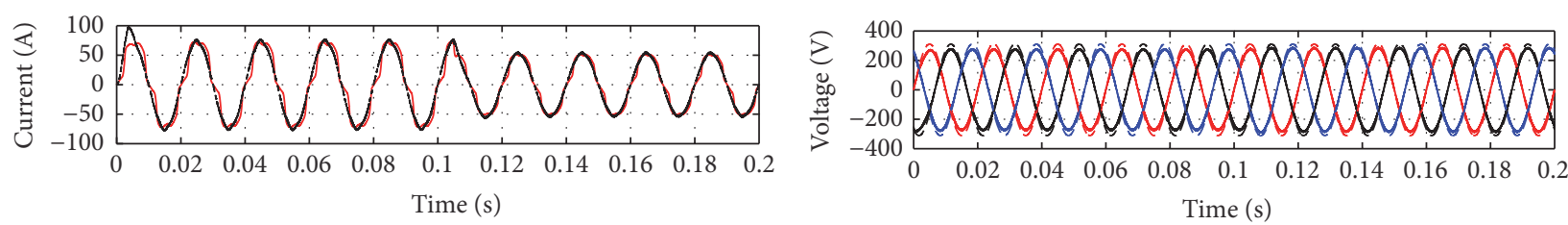

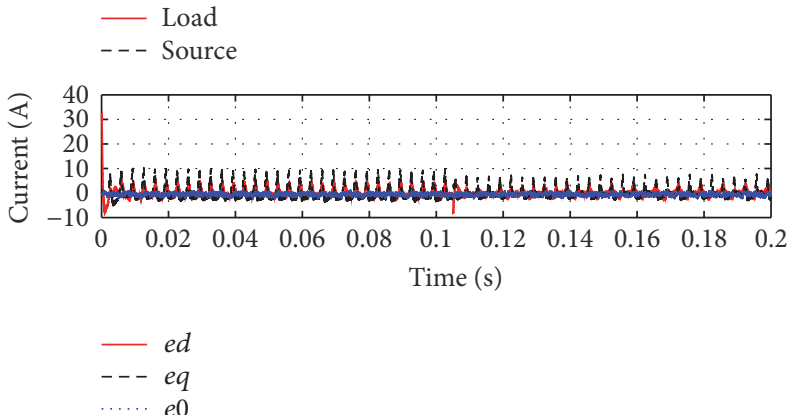

(a) Current results in load change

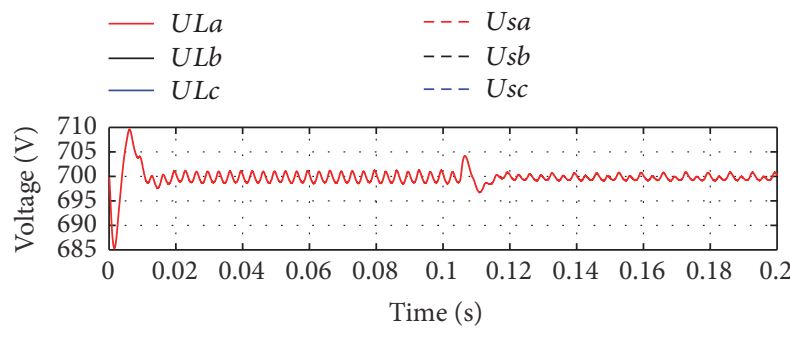

(b) Voltage results in load change

FIGURE 9: Results in load change with PI controller.

THD of small load current is $12.65 \%$, and the THD of source current is $4.96 \%$. When cutting down the nonlinear load, the THD of load current decreases obviously; however, the ratio frequency harmonic increases; thus the THD decreases a little. The load change means the active power change; thus there is an impulse to direct current error $e_{d}$. In Figure 9(b), the load voltage increases when load power change is smaller, which is because the load current decreases and the voltage loss decreases. Also there is an impulse to DC-link voltage.

In Figure 10(a), the upper part is load current and source current, the THD of load current is $16.37 \%$, the THD of source current is $2.58 \%$, the THD of load current is $12.74 \%$, and 

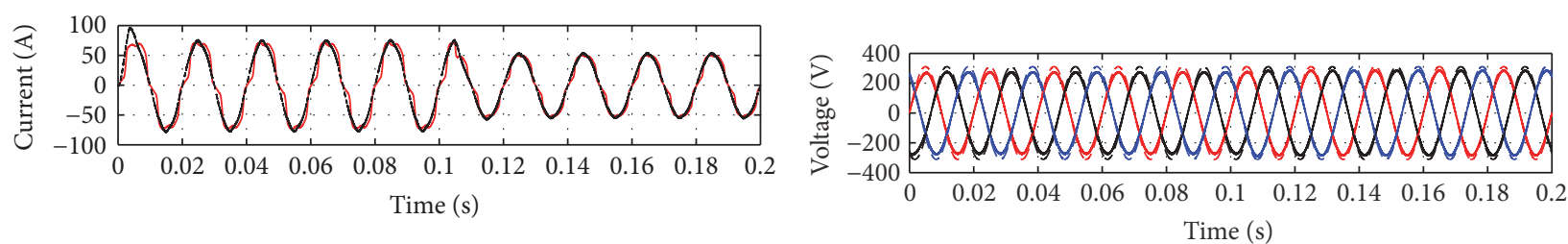

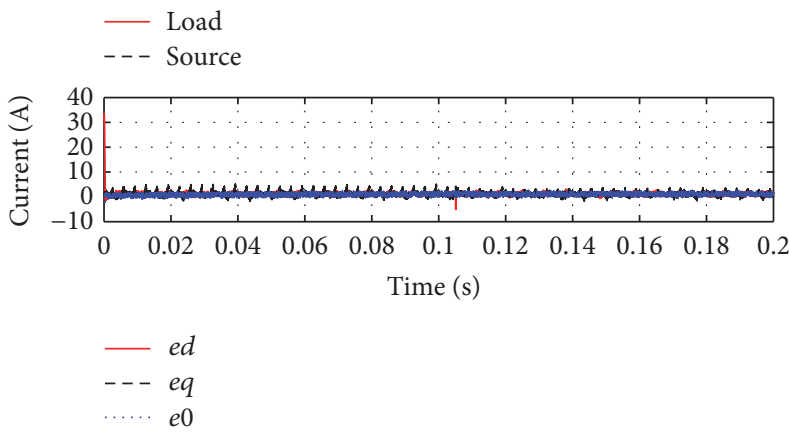

(a) Current results in load change

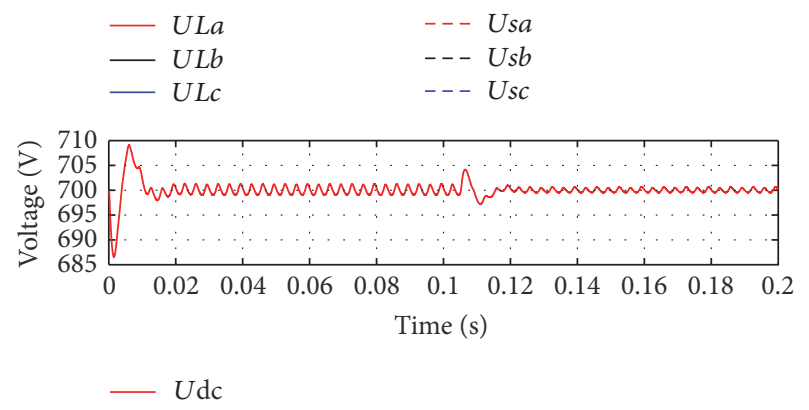

(b) Voltage results in load change

FIgURE 10: Results in load change with FBL-QSMC controller.
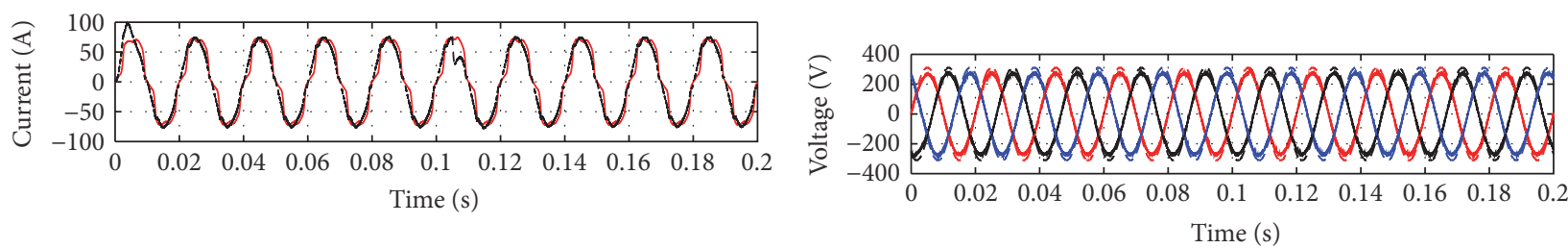

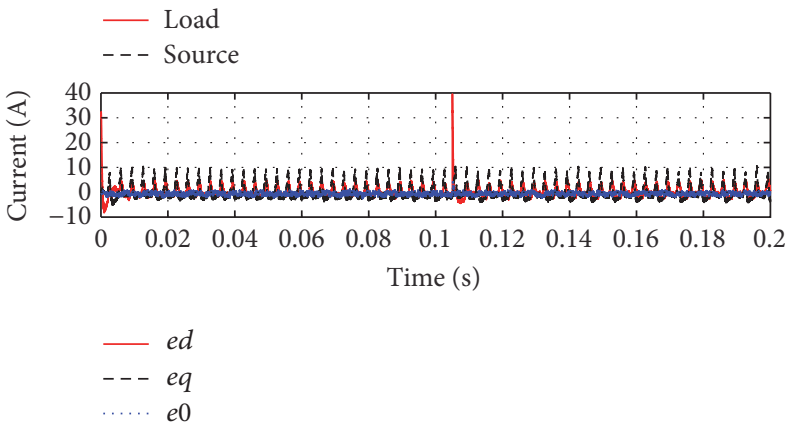

(a) Current results in DC-link voltage change

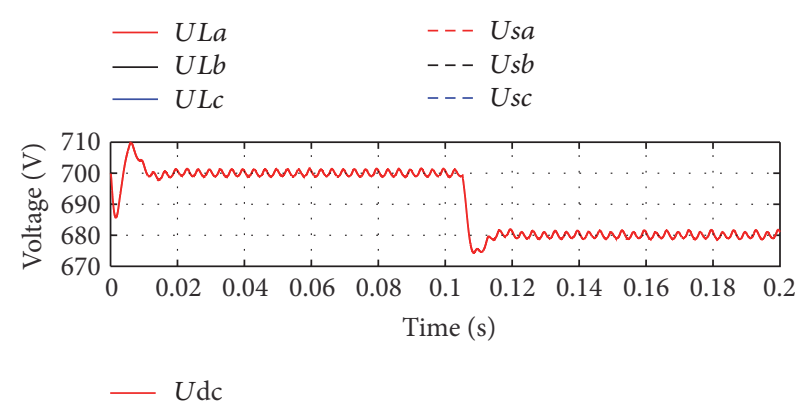

(b) Voltage results in DC-link voltage change

FIGURE 11: Results in DC-link voltage change with PI controller.

the THD of source current is $2.55 \%$. When cutting down the nonlinear load, the THD of load current decreases obviously; however, the ratio frequency harmonic increases; thus the THD decreases a little. There is an impulse to direct current error $e_{d}$; however, convergence is fast; in addition, the direct current error $e_{d}$ and quadrature current error $e_{q}$ are very small. In Figure 10(b), the load voltage increases when load power change is smaller. The DC-link voltage is similar to PI controller, which is because the outer loops are both applying PI control.

5.2. Case 2: DC-Link Voltage Change. The reference DC-link voltage changes from $700 \mathrm{~V}$ to $680 \mathrm{~V}$ at $t=0.105 \mathrm{~s}$; the results in PI controller are shown in Figure 11; the results in FBLQSMC controller are shown in Figure 12.

In Figure 11(a), the upper part is load current and source current, the THD of load current is $16.24 \%$, and the THD of source current is $5.01 \%$. With DC-link voltage decrease, the compensating current track ability decreases. The compensation harmonic increases more than frequency harmonic decrease; thus the THD increases. The DC-link voltage decrease means exporting active power; thus the source current decreases; there is an impulse to direct current error $e_{d}$. In Figure 11(b), the load voltage increases when DClink voltage decreases, which is because the source current decreases and the voltage loss decreases. 

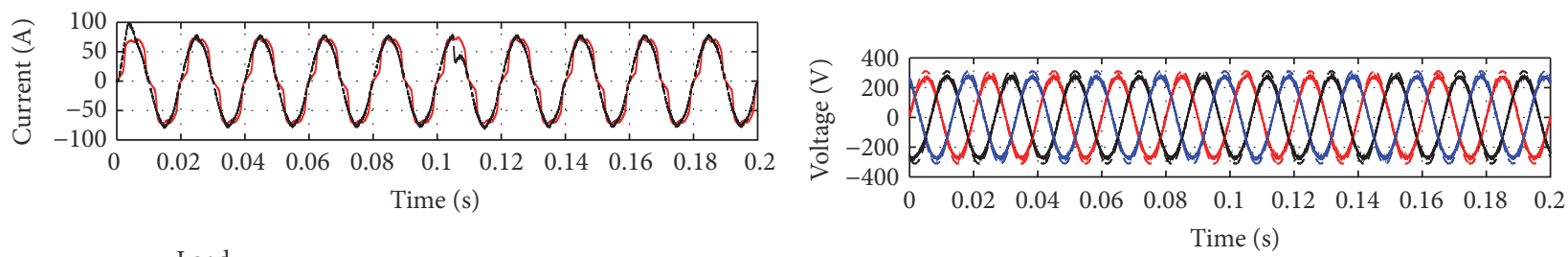

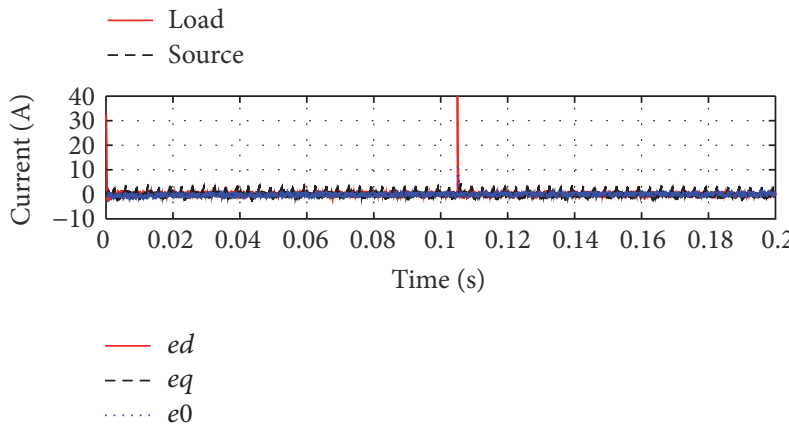

(a) Current results in DC-link voltage change

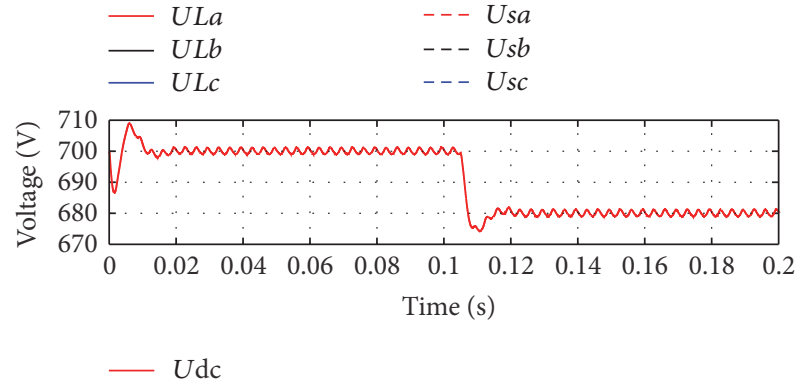

(b) Voltage results in DC-link voltage change

FIGURE 12: Results in DC-link voltage change with FBL-QSMC controller.

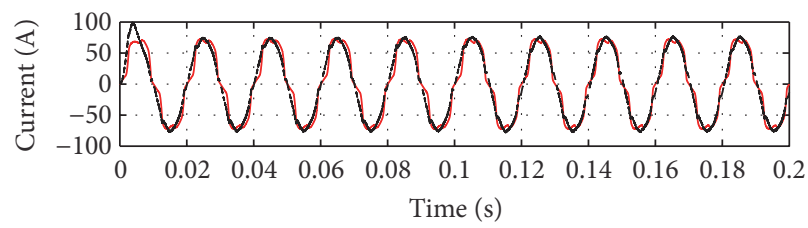

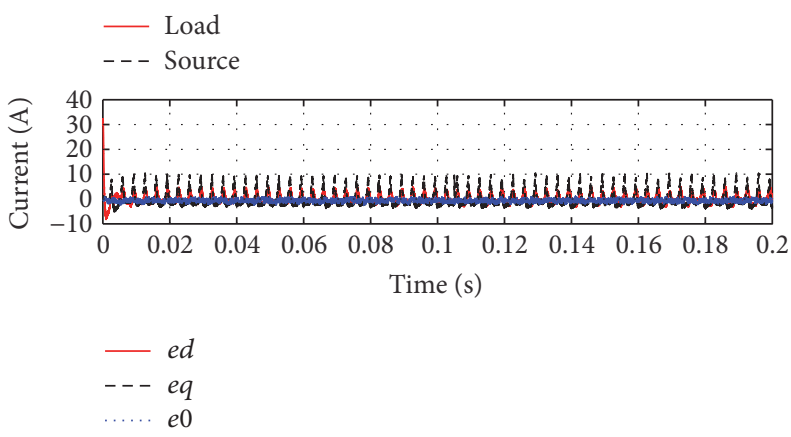

(a) Current results in reactive power change
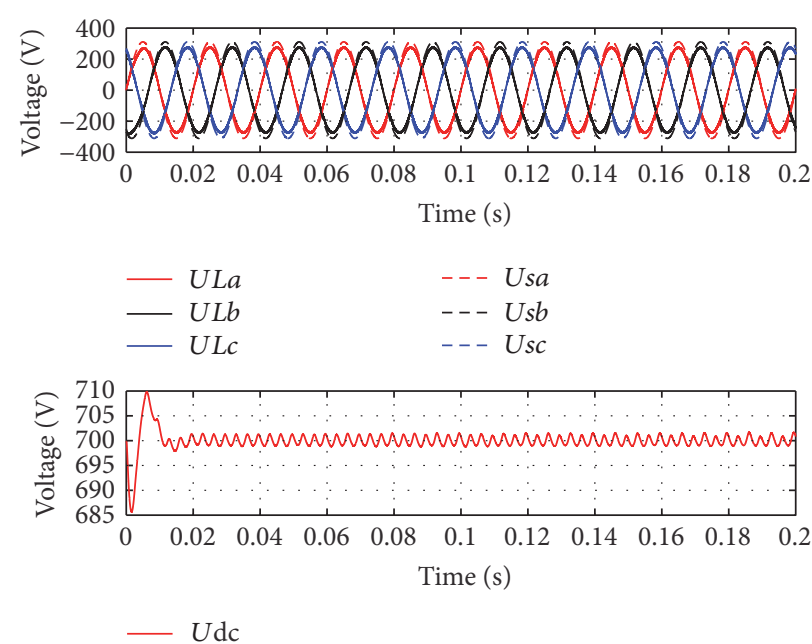

(b) Voltage results in reactive power change

FIGURE 13: Results in reactive power change with PI controller.

In Figure 12(a), the upper part is load current and source current, the THD of load current is $16.37 \%$, and the THD of source current is $2.55 \%$. With DC-link voltage decrease, the compensating current track ability decreases, and the frequency harmonic decreases. The compensation harmonic increases less than frequency harmonic decrease; thus the THD decreases. There is an impulse to direct current error $e_{d}$ and converge fast. In addition, the direct current error $e_{d}$ and quadrature current error $e_{q}$ are very little. In Figure 12(b), the load voltage increases when DC-link voltage change is smaller. The DC-link voltage response is similar to PI controller which is because the outer loops are both applying PI control.
5.3. Case 3: Reactive Power Change. At $t=0.105 \mathrm{~s}$ without reactive power compensation, the results in PI controller are shown in Figure 13; the results in FBL-QSMC controller are shown in Figure 14.

In Figure 13(a), the upper part is load current and source current, the THD of load current is $16.24 \%$, and the THD of source current is $4.95 \%$. Without reactive power compensation the compensating current decreases, which can improve the harmonic current tracking ability; thus the THD decreases. Without reactive power compensation the source current's power angle is equal to the load current's, and there is an impulse to quadrature current error $e_{d}$. In Figure 13(b), the change of reactive power produces a little impact on the load voltage and no impact on DC-link voltage. 

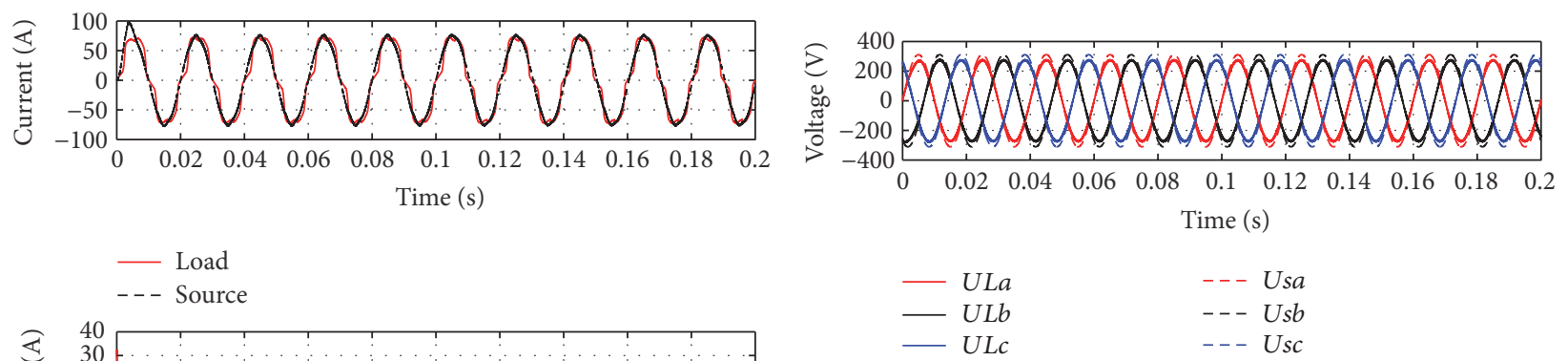

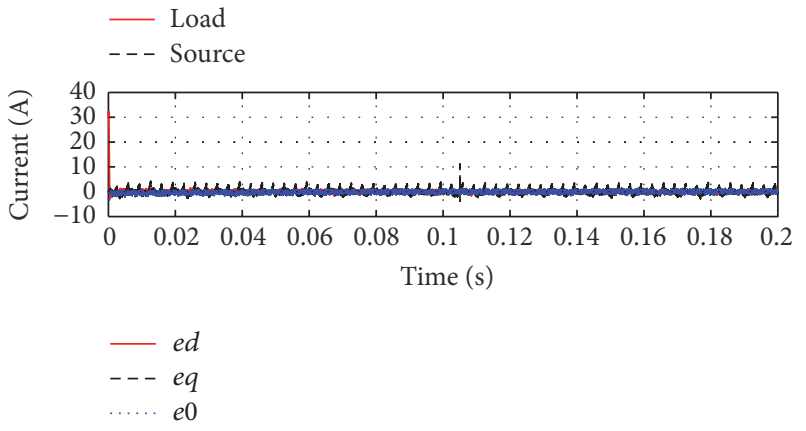

(a) Current results in reactive power change

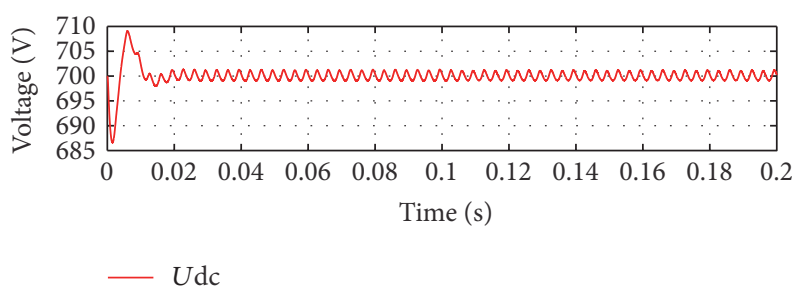

(b) Voltage results in reactive power change

FIGURE 14: Results in reactive power change with FBL-QSMC controller.

In Figure 14(a), the upper part is load current and source current, the THD of load current is $16.37 \%$, and the THD of source current is $2.46 \%$. Without reactive power compensation, there is an impulse to quadrature current. The tracking current error is obviously smaller than in PI controller. In Figure 14(b), with the reactive power change there is little impact on load voltage and no impact on DClink voltage.

\section{Conclusion}

The Bode diagram of traditional simplified model is obviously different with complete model, which means the descriptions of the system based on the traditional simplified model are inaccurate and incomplete. Thus, it is necessary to popularize complete model of APF. The proposed feedback linearization and quasi-sliding mode control algorithm has fast response and robustness; the compensation performance is superior to PI control obviously. The simulation results proved that the complete modeling and proposed control algorithm are correct.

\section{Conflicts of Interest}

The authors declare that they have no conflicts of interest.

\section{Acknowledgments}

This work is supported by the project of "National Natural Science Foundation of China (51577074)" and "Science and Technology Project of China South Grid Corp (GDKJXM00000015).”

\section{References}

[1] W. U. Tareen, S. Mekhilef, M. Seyedmahmoudian, and B. Horan, "Active power filter (APF) for mitigation of power quality issues in grid integration of wind and photovoltaic energy conversion system," Renewable \& Sustainable Energy Reviews, vol. 70, pp. 635-655, 2017.

[2] M. Huang, X. Wang, P. C. Loh, and F. Blaabjerg, "LLCL-filtered grid converter with improved stability and robustness," IEEE Transactions on Power Electronics, vol. 31, no. 5, pp. 3958-3967, 2016.

[3] X. Fu and S. Li, "A novel neural network vector control for single-phase grid-connected converters with L, LC and LCL filters," Energies, vol. 9, no. 5, article no. 328, 2016.

[4] H. Li, J. Zhao, and X. Yang, "Mathematical model of gridconnected inverter system in weak grid," IEEE Electronics Letters, vol. 51, no. 23, pp. 1922-1924, 2015.

[5] X. Bao, F. Zhuo, Y. Tian, and P. Tan, "Simplified feedback linearization control of three-phase photovoltaic inverter with an LCL filter," IEEE Transactions on Power Electronics, vol. 28, no. 6, pp. 2739-2752, 2013.

[6] X. Lu, Y. Xie, and L. Chen, "Feedback linearization and sliding mode control for VIENNA rectifier based on differential geometry theory," Mathematical Problems in Engineering, vol. 2015, Article ID 573016, 2015.

[7] S. R. Mohapatra, P. K. Ray, and G. H. Beng, "A partial feedback linearization based control design and simulation for three phase shunt active power filter," Measurement, vol. 91, pp. 288294, 2016.

[8] J. Matas, L. Garcia de Vicuna, J. Miret, J. M. Guerrero, and M. Castilla, "Feedback linearization of a single-phase active power filter via sliding mode control," IEEE Transactions on Power Electronics, vol. 23, no. 1, pp. 116-125, 2008.

[9] Z. Wang, Y. Mao, Z. Hu, and Y. Xie, "A sliding mode control design based on the reaching law for matrix rectifiers," Journal of Power Electronics, vol. 16, no. 3, pp. 1122-1130, 2016. 
[10] M. P. Aghababa and M. E. Akbari, "A chattering-free robust adaptive sliding mode controller for synchronization of two different chaotic systems with unknown uncertainties and external disturbances," Applied Mathematics and Computation, vol. 218, no. 9, pp. 5757-5768, 2012.

[11] M. Kale, M. Karabacak, W. Kruschel, F. Kilic, and P. Zacharias, "Chattering free robust control of LCL filter based shunt active power filter using adaptive second order sliding mode and resonant controllers," International Journal of Electrical Power \& Energy Systems, vol. 76, pp. 174-184, 2016.

[12] Y. Wang, Y. Xie, and Z. Wang, "Linear quadratic regulator control of LC active power filter without reference current detection," IEICE Electronics Express, vol. 14, no. 18, pp. 1-12, 2017.

[13] C.-S. Wang and M.-H. Chiang, "A novel pitch control system of a large wind turbine using two-degree-of-freedom motion control with feedback linearization control," Energies, vol. 9, no. 10, article no. 791, 2016.

[14] I. M. Boiko, "Chattering in sliding mode control systems with boundary layer approximation of discontinuous control," International Journal of Systems Science, vol. 44, no. 6, pp. 11261133, 2013.

[15] H. Li, K. Zhang, and H. Zhao, "DC-link active power filter for high-power single-phase PWM converters," Journal of Power Electronics, vol. 12, no. 3, pp. 458-467, 2012. 


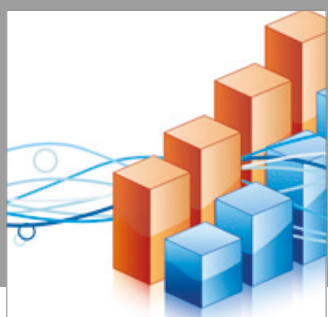

Advances in

Operations Research

vatersals

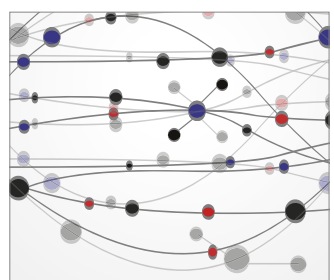

\section{The Scientific} World Journal
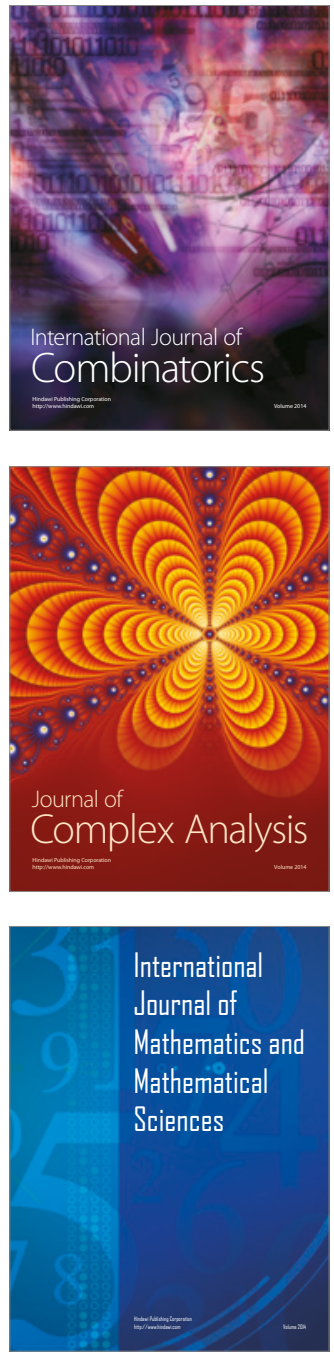
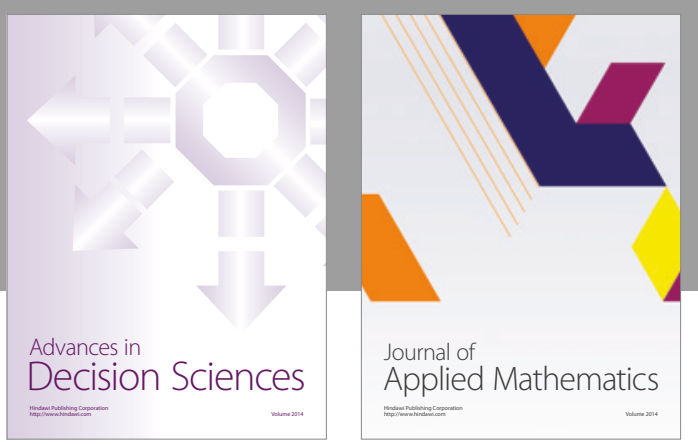

Algebra

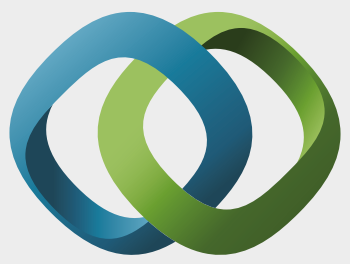

\section{Hindawi}

Submit your manuscripts at

https://www.hindawi.com
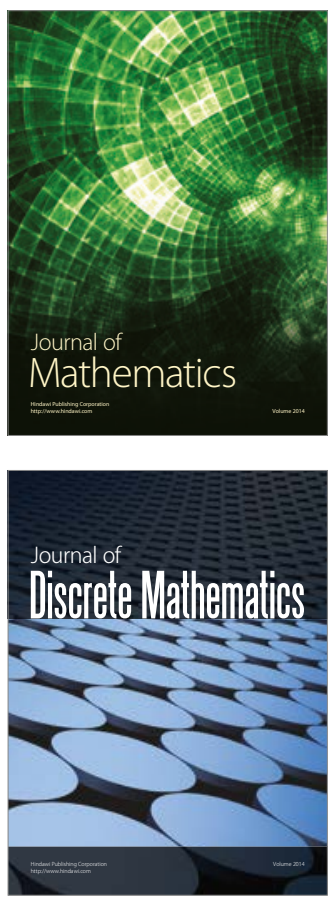

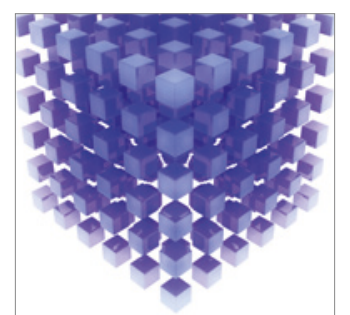

Mathematical Problems in Engineering
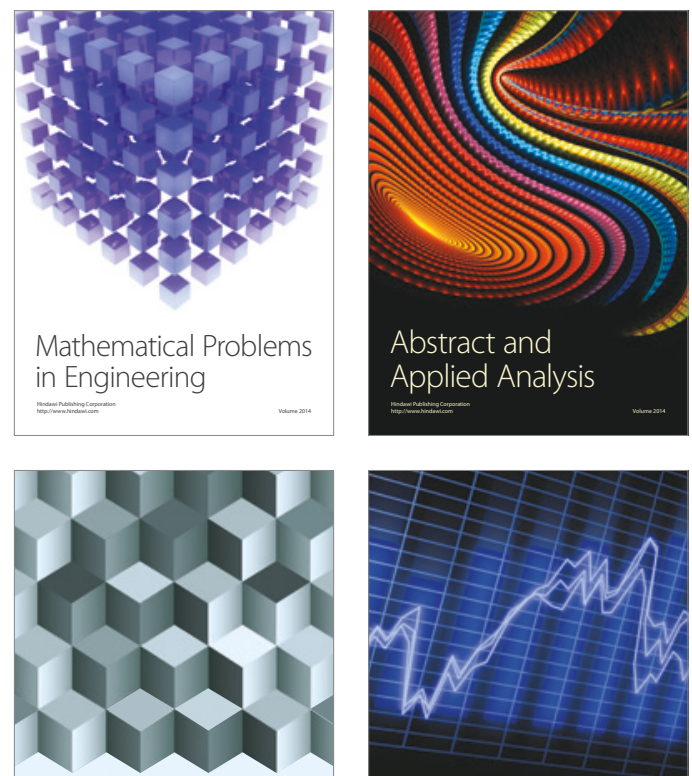

Journal of

Function Spaces

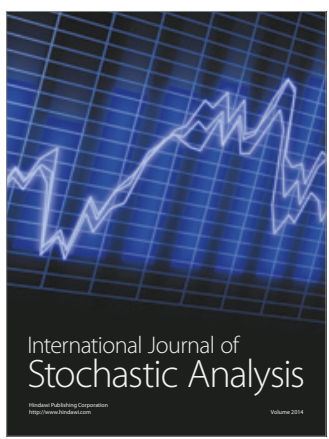

Probability and Statistics
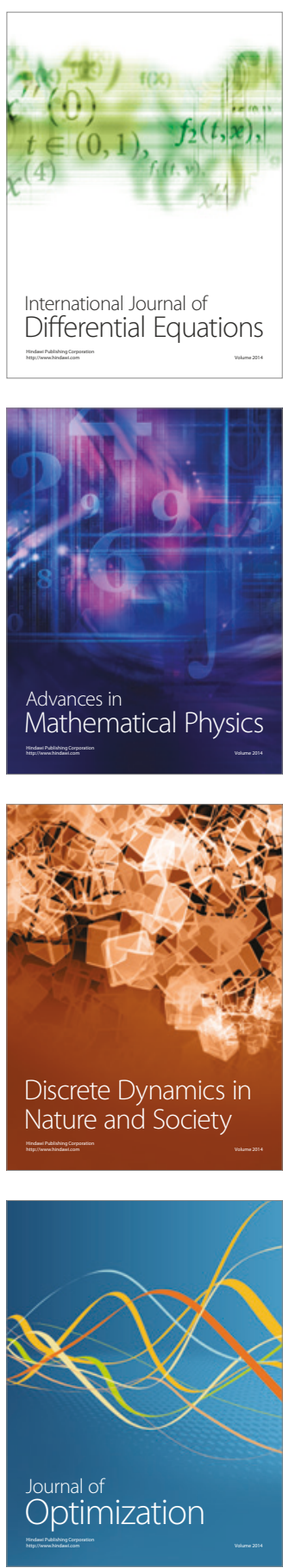